\title{
Designing educational software inline with the creative learning process: Just how important is the preparation phase?
}

\author{
Sylvia M. Truman \\ Knowledge Media Institute \\ The Open University \\ Milton Keynes, MK7 6AA \\ +44 (0)1908 645771 \\ s.m.truman@open.ac.uk
}

\begin{abstract}
A question gaining widespread interest in education today is 'how can learning tasks be structured to encourage creative thinking in the classroom?' This has a number of implications for the design of educational software. Numerous scholars have suggested that the processes of 'learning' and 'creativity' share many similarities. Extending upon this a generative framework of creative learning is presented here. This framework exists as a design support tool to aid the design of educational software. In order to demonstrate how this framework can be applied in practice, a music composition program called 'SoundScape' has been developed in accordance with the framework. This paper reports upon study conducted with SoundScape within a school with 96 children aged 11. The study focused upon two objectives, firstly, identifying differences in explicitly supporting the "preparation" phase of the creative process as opposed to not explicitly supporting the "preparation" phase. Secondly, the study compared differences in using real-world metaphors at the interface compared to using visual abstract representations at the interface.
\end{abstract}

\section{General Terms}

Design, Theory, Verification.

\section{Keywords}

Constructivist learning theory, constructionism, creativity, collaboration, music learning

\section{INTRODUCTION}

This paper emphasises the importance of designing educational technology inline with the creative process. In particular this paper focuses upon the importance of designing technology to explicitly support the 'preparation phase' of the creative process. In order to investigate this, this paper reports upon a

(c) Sylvia Truman, 2007

Published by the British Computer Society Volume 2 Proceedings of the 21st BCS HCI Group Conference

HCI 2007, 3-7 September 2007, Lancaster University, UK Devina Ramduny-Ellis \& Dorothy Rachovides (Editors) study using the music composition program SoundScape. The design of SoundScape was guided by the generative framework of creative learning [1]. This paper reports upon the findings of the study.

\section{THEORETICAL BACKGROUND: CREATIVIY \& REPRESENTING MUSIC}

\subsection{The creative process}

Wallas (1926) formalised the four stage model, representing the creative process [2]. This model consists of four stages; preparation, incubation, illumination and verification. Preparation concerns immersing one's self within a domain and developing a curiosity about a particular problem [3]. At this stage, an individual will also consciously accumulate knowledge and draw upon influences from previous experience. During the incubation stage, conscious thought pertaining to the problem is rested and left to the unconscious mind [4]. Illumination occurs when one experiences a sudden flash of insight [5]. Finally, verification concerns forming judgements pertaining to the creative artefact produced. A number of scholars have continued to apply the four stage model as a basis for understanding creativity [6] [7], while others have extended upon it [8] [9].

\subsection{Specifying musical representations}

Visual imagery is widely acknowledged as a crucial element of creative thinking [10], therefore, it is common sense to incorporate visual imagery into the design of creative learning environments. In relation to music composition software, music has been typically specified using staff notation. However, more recent studies into musical representations have reported that music notation may act as an inhibitor of musical creativity [11] [12] [13] [14], owing to the mis-match between the sound properties of music and the visual specification of staff notation.

\section{A generative framework for creative learning}

Drawing on the above, a framework which represents a distillation of creativity theory is presented, focusing upon education. This framework is presented in the form of a generative framework, which exists as a design support tool to 
assist the design of creative educational experiences for the classroom (see figure 1). Wallas's four-stage model has been adapted as the fundamental basis for this framework, with the processes of preparation, generation and evaluation represented laterally across the framework. The vertical dimensions reflect individual (denoted here as personal) and social components of creativity. The 'social' level refers to others, peers and society. Whereas, 'personal' levels reflect explicit and tacit levels of thinking.

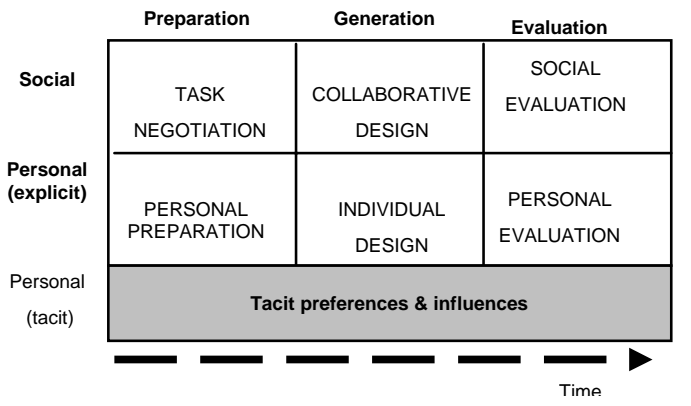

Figure 1. A generative framework for creative learning

With regard to figure 1 , the processes of preparation, generation and evaluation are three integral concepts of the creative process. Every creative act involves the preparation of ideas. At a personal level, an individual will develop a curiosity or a desire to create. Once this desire has been established, information is consciously accumulated from the external environment and thoughts may be discussed with others on a 'social' level which the individual can reflect upon. If working in a collaborative setting, group-wide negotiations of the task will also take place. Inevitably, the way in which an individual prepares for the task will be influenced by their past experiences [15].

The generation process of the framework encompasses social and personal design. Within this process ideas are generated which can involve negotiation between the individual and peers in their environment. Additionally, idea generation is assisted partly by a continuous dialogue which occurs between conscious thought at the personal explicit level and subconscious processing at the tacit level. The evaluation process concerns reviewing early creative ideas through to evaluating the final artefact. Evaluation may occur at a personal level, or at a wider (community) level. It is emphasised that the framework does not commit to a strict linear route, rather the creative process is cyclic in nature. Therefore, the review of creative ideas may result in a need to revise ideas which may result in further preparation, or evaluation or further generation and so on. The processes of the framework are not mutually exclusive, as in some instances processes within the framework may overlap. The framework can be used as a design support tool to facilitate creative thinking in the classroom by ensuring that preparatory materials are scaffolded to the six component boxes of the framework.

\section{RESEARCH QUESTIONS \& PLANNING THE STUDY}

Extending upon the theoretical background and the generative framework, two questions were raised. Firstly, what different outcomes may arise when the software explicitly supports / does not support the preparation phase? Secondly, what different outcomes may arise when real-world metaphors are used to specify music as opposed to abstract representations? In order to investigate these questions, four different prototypes of SoundScape were designed.

\subsection{SoundScape prototypes}

With prototype one, students prepare for the task by specifying their 'composition' object by associating real-world metaphors with pre-recorded music samples. After creating eight objects students then progress to the composition screen whereby objects are placed on the composition background using drag and drop functionality (see figure 2). This prototype has been designed to explicitly support preparation whilst using realworld metaphors to specify music. With Prototype two, preparation is not explicitly supported and students enter the program at the generation phase (i.e. composition screen) and create a composition using pre-selected objects. Prototype three uses abstract representations to specify music, similar to those used in off the shelf programs such as the E-Jay range. Preparation is supported by allowing students to select eight music samples to use for their composition. After selecting eight music samples students progress to the composition screen and place the objects on the screen using drag and drop functionality (see figure 3). Prototype four does not support preparation and students enter the program at the composition screen using pre-selected objects which are abstract representations of music is with prototype three.
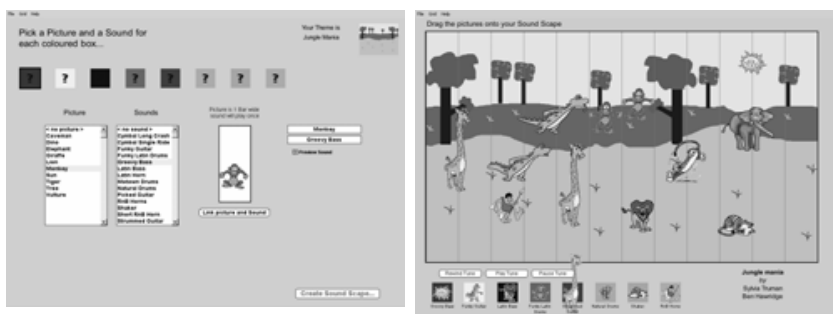

Figure 2. Screen shots of prototypes 1 and 2
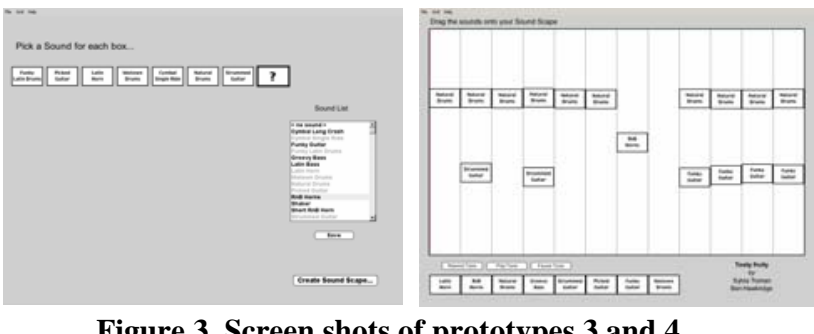

Figure 3. Screen shots of prototypes 3 and 4

\subsection{Experimental conditions}

In order to investigate the research questions, each prototype was assigned to one of four experimental conditions as show in table 1. Ninety six school children participated with the study, all eleven years of age. Twenty four participants were allocated to each of the conditions, with twelve pairs of students in each condition. The study conducted with one pair at a time to allow participants to work free from distraction. Prior to interacting with SoundScape, participants were instructed: "working as a pair, create a piece of music using SoundScape. There is no 
right or wrong way of carrying out this task. Spend as long as necessary until you feel you have completed the task.

Table 1. Experimental conditions used in study

\begin{tabular}{|l|l|l|}
\hline CONDITION & $\begin{array}{c}\text { PREPARATION } \\
\text { SUPPORT? }\end{array}$ & $\begin{array}{c}\text { REPRESENTATION } \\
\text { USED }\end{array}$ \\
\hline V-P & Yes & Visual metaphor \\
\hline V-NP & No & Visual metaphor \\
\hline NV-P & Yes & Abstract representation \\
\hline NV-NP & No & Abstract representation \\
\hline
\end{tabular}

Data was collected during the participant's session both by the program and behaviour analysis. Outcomes of the study are now discussed in terms of: time on task, manipulation of composition objects used, and points of pair-wise discussion.

\section{RESEARCH FINDINGS ARISING FROM THE STUDY}

Outcomes were compared across the four conditions in terms of the time spent on the composition task, the number of composition objects moved during the session, the number of musical bars used, the number of the eight available objects used, the number of discussion points made about individual sound samples, the number of discussion points made about individual pictures, and the number of discussion points made about mapping (i.e. the association between the music samples and pictures).

\subsection{Time on task}

Results indicate that those working within preparation conditions V-P and NV-P spent significantly longer on the task than those in non-preparation conditions V-NP and NV-NP. Findings also indicate that those working with visual metaphors to specify music (i.e. V-P and V-NP) spent significantly longer on the task than those using abstract representations (i.e. NV-P and NV-NP).

\subsection{Object manipulations}

Results indicate that those using visual metaphors moved significantly more objects than those using an abstract representation to specify music. No significant differences were reported between preparation and non-preparation conditions. Those using visual metaphors to specify music used significantly more musical bars than those using abstract representations. Again, no significant differences were reported when comparing preparation and non-preparation conditions. With regard to the number of the eight available composition objects used, those using visual metaphors to specify music used significantly more of the 8 objects than those using abstract representations. When comparing preparation and nonpreparation conditions, those working within the preparation conditions used significantly more of the 8 objects.

\subsection{Pair wise discussion points}

In terms of discussions that took place within the pairs as student worked on their compositions, results indicate that those using the abstract representation to specify music made significantly more sound comments than those using visual metaphors. No significant differences were identified when comparing preparation and non-preparation conditions. With regard to discussion points concerning individual pictures (i.e. metaphors used), those within the preparation condition (V-P) made significantly more comments concerning pictures as opposed to those within the non-preparation condition (V-NP). With regard to mapping discussion points, those in the preparation condition (V-P) made significantly more mapping discussion points than those within the non-preparation condition (V-NP). These findings are summarised in table 2.

Table 2. Summary of findings

\begin{tabular}{|l|l|l|}
\hline OUTCOME & $\begin{array}{l}\text { TASK } \\
\text { SUPPORT }\end{array}$ & REPRESENTATION \\
\hline Time on task & $\begin{array}{l}\text { Those in } \\
\text { preparation } \\
\text { conditions } \\
\text { spent longer on } \\
\text { the task. }\end{array}$ & $\begin{array}{l}\text { Those in visual metaphor } \\
\text { conditions spent longer } \\
\text { on the task. }\end{array}$ \\
\hline $\begin{array}{l}\text { No. of } \\
\text { composition } \\
\text { objects moved }\end{array}$ & $\begin{array}{l}\text { No significant } \\
\text { differences. }\end{array}$ & $\begin{array}{l}\text { Those in visual metaphor } \\
\text { conditions moved more } \\
\text { objects. }\end{array}$ \\
\hline $\begin{array}{l}\text { No. of available } \\
\text { bars used }\end{array}$ & $\begin{array}{l}\text { No significant } \\
\text { differences. }\end{array}$ & $\begin{array}{l}\text { Those in visual metaphor } \\
\text { conditions used more of } \\
\text { the musical bars. }\end{array}$ \\
\hline $\begin{array}{l}\text { No. of eight } \\
\text { composition } \\
\text { objects used }\end{array}$ & $\begin{array}{l}\text { Those in } \\
\text { preparation } \\
\text { conditions } \\
\text { used more of } \\
\text { the eight } \\
\text { available } \\
\text { objects. }\end{array}$ & $\begin{array}{l}\text { Those in visual metaphor } \\
\text { conditions used more of } \\
\text { the eight objects. }\end{array}$ \\
\hline $\begin{array}{l}\text { No. of sound } \\
\text { discussion } \\
\text { points }\end{array}$ & $\begin{array}{l}\text { No significant } \\
\text { differences. } \\
\text { discussion } \\
\text { points }\end{array}$ & $\begin{array}{l}\text { Those in abstract } \\
\text { representation conditions } \\
\text { made more sound } \\
\text { comments. }\end{array}$ \\
\hline $\begin{array}{l}\text { No. of picture } \\
\text { discussion point }\end{array}$ & $\begin{array}{l}\text { Those in the } \\
\text { preparation } \\
\text { condition made } \\
\text { more picture } \\
\text { comments. } \\
\text { condition made } \\
\text { more mapping } \\
\text { comments. }\end{array}$ & N/A \\
\hline N/A
\end{tabular}

\section{CONCLUSIONS: PULLING THE THREADS TOGETHER}

In answer to original question: "How can learning tasks be structured to encourage creative thinking in the classroom"? This study has attempted to provide a solution through the presentation of the generative framework.

The design of educational technologies can be assisted by this framework, which can be applied to differing domains of the curriculum. This paper has also demonstrated the application of the framework in practice through the music composition program SoundScape which has been used as a vehicle through which to address the research questions. Outcomes of the study suggest that preparation is a crucial element of the creative process and that supporting task preparation during system 
design can help to encourage creative thinking. Outcomes also suggest that the use of visual imagery is a useful tool for learning, especially where imagery used is consistent with realworld artefacts.

\section{ACKONWLEDGEMENTS}

The author acknowledges and extends appreciation to Ben Hawkridge (Knowledge Media Institute, The Open University) for his assistance with developing the SoundScape program.

\section{REFERENCES}

[1] Conference paper: Truman, S.M \& Mulholland, P (2006) Designing educational software to enhance the creative learning experience: An integrative framework. Proceedings of HCI 2006 Engage. $11^{\text {th }}-15^{\text {th }}$ September. Queen Mary, University of London.

[2] Book: Wallas (1926) The Art of Thought. Jonathan Cape [republished in 1931]. London.

[3] Chapter: Getzels, J.W (1964) Creative Thinking, ProblemSolving, and Instruction. In E.R. Hilgard (Ed), Theories of Learning and Instruction. University of Chicago Press. Chicago.

[4] Book: Claxton (1998) Hare Brain Tortoise Mind: Why Intelligence Increases When you Think Less. Fourth Estate Limited. London.

[5] Citation: Poincare (1913) in Leytham, G (1990) Managing Creativity. Peter Francis Publishers. Norfolk.

[6] Book: Osche, R (1990) Before the Gates of Excellence: The Determinants of Creative Genius. Cambridge University Press.

[7] Journal article: Goswami, A (1996) Creativity and the quantum: A unified theory of creativity. Creativity Research Journal. 9. p $47-61$.
[8] Book: Amabile, T.M (1996) Creativity in Context. Westview. Boulder, CO.

[9] Chapter: Runco, M.A \& Dow, G (1999) Problem Finding. In Runco, M.A \& Pritzker, S.R (Eds) Encyclopedia of Creativity. (Vol. 2). P 433 - 435. Academic Press. San Diego.

[10] Book chapter: Gruber, H. E \& Wallace, D. B (1999) The case study method and evolving systems approach for understanding unique creative people at work. In Sternberg, R. J (Ed) Handbook of Creativity. pp 93 - 115. Cambridge UK; Cambridge University Press.

11] Book chapter: Walker, R (1992) Auditory-visual perception and musical behaviour. In Colwell, R. (Ed) Handbook of Research on Music Teaching and Learning. New York; Schirmer Books.

[12] Doctoral dissertation: Auh, M (1996) Prediction of musical creativity in composition amongst selected variables for upper elementary students. (Doctoral Dissertation, Case Western Reserve University, Cleveland, Ohio, USA, 1995). Dissertation Abstracts International. 56, 3875A

[13] Journal article: Auh, M. (1997). Prediction of musical creativity in composition among selected variables for upper elementary students. Bulletin of the Council for Research in Music Education, 133, 1-8.

[14] Conference paper: Auh, M (2000) Effects of using graphic notations on creativity in composing music by Australian secondary school students. Proceedings of the Australian Association for Research in Education Conference. Australia 2000.

[15] Technical report: Schank, R (1995) What we Learn when we Learn by Doing. Northwestern University, Institute for Learning sciences. 